\title{
Pathogenesis of idiopathic nephrotic syndrome in children: molecular mechanisms and therapeutic implications
}

\author{
Samuel N Uwaezuoke \\ Pediatric Nephrology Firm, University of Nigeria Teaching Hospital, Ituku-Ozalla, Enugu, Nigeria
}

\begin{abstract}
The conventional paradigm on the pathogenesis of nephrotic syndrome revolves around the concept of a glomerular disorder which is characterized by massive proteinuria with consequent hypoalbuminemia, generalized edema and hyperlipidemia. However, the changes at structural and molecular levels of the podocytes have recently assumed prominence as a new paradigm on the pathogenesis of pediatric idiopathic nephrotic syndrome. A number of complex molecular pathways with inter-related nexus result in a molecular disorientation of the slit diaphragm or the glomerular basement membrane leading to proteinuria, as well as in a rearrangement of the podocyte cytoskeleton which is responsible for foot process effacement. In acquired podocytopathies such as focal segmental glomerulosclerosis and minimal change disease, the molecular changes observed in proteins from the cytoskeleton, cell transmembrane, and the slit diaphragm induce foot process effacement and changes in negative charges which eventuates in massive proteinuria. Development of drugs able to affect these molecular pathways that regulate podocyte injury offers hope for targeted and effective treatments for nephrotic syndrome in future. Moreover, the causal association between multiple genetic mutations and the podocytopathies may translate into novel therapeutic approaches in their treatment. This review will discuss the recent hypothesized molecular mechanisms involved in the pathogenesis of idiopathic nephrotic syndrome (the podocytopathies), and the therapeutic implications.
\end{abstract}

\section{Introduction}

The conventional paradigm on the pathogenesis of nephrotic syndrome revolves around the concept of a glomerular disorder which is characterized by massive proteinuria with consequent hypoalbuminemia, generalized edema and hyperlipidemia [1]. The glomerular capillary wall (responsible for ultrafiltration) is a trilaminate structure consisting of the basement membrane covered on the inner surface by fenestrated endothelium and wrapped around the outer surface by the podocytes. Under electron microscopy, disruption of this glomerular filter seen in many acquired and inherited nephropathies is associated with a diffuse effacement of the podocyte foot processes [2]. This effacement suggests a key role for the podocytes in the pathogenesis of idiopathic nephrotic syndrome, either as a target of a glomerular permeability factor or as the site of alteration of a structural component of the foot processes [2]. In fact, the major idiopathic glomerulopathies associated with proteinuria are the podocytopathies (minimal change disease and focal segmental glomerulosclerosis), as well as membranous nephropathy. The former are commoner in children than the latter.

The podocytopathies are characterized by changes in the podocytes, which may be at the structural or molecular levels [3]. The changes at the molecular levels have recently assumed prominence as a new paradigm on the pathogenesis of idiopathic nephrotic syndrome in children. In addition, emerging data suggest that steroid-sensitive nephrotic syndrome, as well as a subset of steroid-resistant nephrotic syndrome (particularly those recurring after transplantation) have an immunological basis [3]. For instance, it appears that $\mathrm{T}$ cells in these patients promote the production of a circulating factor, which alters the permeability of the glomerular filtration barrier.

Many vascular permeability factors have been postulated, and these include vascular endothelial growth factor, heparanase, hemopexin and soluble urokinase receptor (suPAR) [4,5]. In addition, podocytes have been found to express receptors for type 2 cytokines (interleukin- 4 and interleukin-13) elaborated by T cells, which if activated may also disrupt glomerular permeability leading to proteinuria [6]. In a nut-shell, idiopathic nephrotic syndrome has been defined as a T-cell disorder associated with a functional renal impairment in which the molecular mechanisms leading from the stimulation of the immune system to the clinical expression of the renal disease can be analyzed according to five biological events: a Th 2 activation of $\mathrm{T}$ cells by interleukin-13; a yet unresolved glomerular permeability factor of immune origin; a molecular disorientation of slit diaphragms or glomerular basement membrane responsible for proteinuria; a podocyte cytoskeleton rearrangement responsible for foot process effacement; and renal avidity for sodium and edema formation resulting from a primary stimulation of tubular sodium, $\mathrm{K}^{+}$-ATPase and an increase of endothelial permeability [7].

This review will discuss the recent hypothesized molecular mechanisms involved in the pathogenesis of idiopathic nephrotic syndrome (the podocytopathies), and the therapeutic implications.

\section{Podocytopathies: The molecular basis}

The podocyte contributes in maintaining the structural integrity of the glomerular filtration barrier as its injury and loss results in

Correspondence to: SN Uwaezuoke, Department of Pediatrics, UNTH, ItukuOzalla, Enugu, Nigeria, Tel: +2348033248108; E-mail: snuwaezuoke@yahoo.com

Key words: podocytopathies, children, molecular mechanisms, therapeutic implications

Received: December 06, 2015; Accepted: December 24, 2015; Published: December 28, 2015 
proteinuria and progressive sclerosis [8]. At the molecular level, focal adhesion kinase (FAK) is prominently involved in the effacement of the foot processes commonly seen in podocytopathies $[9,10]$. Changes in podocyte proteins such as nephrin and nephrin homologue- Neph1 [11], CD2-associated protein (CD2AP) [12,13] and podocin [14], all play an important role in the pathogenesis of podocytopathies. Nephrin is a vital component of the slit diaphragm and also functions as an effective recruiter of other proteins such as podocin and CD2AP [15]. Some authors suggest the existence of an important interaction between actin cytoskeleton structure and these components of the slit diaphragm namely podocin, nephrin and CD2AP $[16,17]$. Thus, in the nephrotic syndromes, there are changes in the podocytes which manifest as effacement of the podocyte foot processes, as well as structural alterations in the cytoskeleton and molecular reorganization of the slit diaphragm [18]. The molecular composition of the actin cytoskeleton (the skeletal structure of the foot processes) consists of actin, $\alpha$-actinin, and synaptopodin $[19,20]$. Notably, the up-regulation of $\alpha$-actinin is accompanied by cytoskeleton reorganization in some nephrotic syndromes [21], while the expression of synaptopodin is generally preserved in minimal change disease, but reduced in focal segmental glomerulosclerosis [22]. Podocalyxin is a molecule thought to be responsible for the stability of the foot processes $[21,23]$, and is shown to be increased in nephrotic syndromes [24]. Another molecular component of the podocyte membrane is GLEPP-1 (a transmembrane tyrosine-phosphatase) which might function as a receptor [25] or regulate both blood pressure and glomerular filtration rates [26]. The expression of GLEPP-1 appears to be down-regulated in focal segmental glomerulosclerosis but assumes normal levels in minimal change disease [27]. Furthermore, the expression of other podocyte cytoskeleton-bound proteins, such as the dystroglycans, is not altered in focal segmental glomerulosclerosis, but is decreased in active minimal change disease [28]. Yet another trans-membrane protein which might be directly involved in the pathogenesis of idiopathic nephrotic syndrome is the B7-1 molecule (CD80); it is commonly located only in the cell surface of B lymphocytes and antigen-presenting cells $[29,30]$. Some investigators have demonstrated that under stress B7-1 might be expressed on podocytes, which may cause reorganization of actin cytoskeleton and modulation of the molecular components of the slit diaphragm [31]. Again, the roles of elevated glomerular profibrotic cytokines such as interleukin-13 and interleukin- 4 and elevated TGF- $\beta$ levels in the pathogenesis of glomerular sclerosis seen in focal segmental glomerulosclerosis have been documented [32-36]. The TGF- $\beta$ signaling pathway may act as a key mediator in cellular mechanisms responsible for glomerulosclerosis and interstitial fibrosis [37]. Elevated TGF- $\beta 1$ production might induce the expression of integrin-linked kinase (ILK), a protein which is related to the pathogenesis of many nephropathies associated with proteinuria. The upregulation of ILK in the podocytes may determine the occurrence of epithelial-mesenchymal transition (EMT) in these cells [38]; these changes may lead to damage in glomerular filtration barrier resulting in proteinuria [39-41].

Finally, the role of Angiopoietin-like 4 (Angpl4) as mediator of persistent proteinuria and hyperlipidemia in minimal change disease remains an interesting update as the molecule holds prospects for novel therapeutic interventions in nephrotic syndrome [42]. In the circulation, a normosialylated form of Angpl4 binds to glomerular endothelial av $\beta 5$ integrin to reduce proteinuria, or inactivates endothelium-bound lipoprotein lipase to reduce the hydrolysis of plasma triglycerides to free fatty acids resulting in hyperlipidemia [43]. Conversely, podocytes in minimal change disease produce a hyposialylated form of Angpl4 which remains confined to the kidney and induces proteinuria [44].

\section{Therapeutic implications of the new paradigm on pathogenesis}

Acquired podocytopathies (focal segmental glomerulosclerosis and minimal change disease) are considered as immunological diseases. Although the data on direct effects of immunosuppressive agents on proteinuria induced by podocyte dysfunction remain controversial, medications like glucocorticoids and calcineurin inhibitors have been noted to exert direct effects on podocytes through regulation of the cytokines (interleukin-4 and interleukin-13) and several signaling pathways responsible for stabilizing the actin cytoskeleton, cell maturation and survival, as well as the expression and distribution of key components of the slit diaphragm [8]. The therapeutic effectiveness of steroids in minimal change disease and calcineurin inhibitors in focal segmental glomerulosclerosis is well established; the nonimmunological actions of calcineurin inhibitors actually include effects on the podocyte cytoskeleton and podocyte survival [8]. Better still, development of drugs which can affect the molecular pathways responsible for regulation of podocyte injury offers hope for targeted and effective treatments for nephrotic syndrome in future [45].

Secondly, the new knowledge about the existence of multiple mutations of the podocyte proteins which can cause nephrotic syndrome [46-48], has led to a more functionally applicable classification of the causes of the syndrome into 'podocytopathies' for mutations directly affecting podocyte structure or function, or 'channelopathies' for mutations affecting an ion channel such as the gene- TRPC6 [49]. A major treatment challenge in childhood nephrotic syndrome is that it is clearly not a single-disease entity more so with the multiple genetic mutations causally associated with it; examples of affected genes include NPHS 1, NPHS 2, CD2AP, PLCE 1, LAMB 2, ACTN 4, TRPC 6, INF 2 and ARHGAP 24 [48-52]. In future, this new concept on the grouping of the causes of nephrotic syndrome may translate into new therapeutic approaches in its treatment. Finally, another molecular mechanism with therapeutic implication is the pro-proteinuric action of podocyte-producing hyposialylated Angpl4; the mutant form of this protein molecule has the therapeutic potential as an anti-proteinuric agent $[43,44]$.

\section{Conclusions}

The molecular mechanisms involved in the pathogenesis of idiopathic nephrotic syndrome are complex and depend on all the components of the glomerular filtration barrier. The plethora of podocyte molecules which form part of this trilaminate barrier and their identified gene mutations has opened up a new understanding on the non-syndromic causes of nephrotic syndrome. The podocyte which contributes in maintaining the structural integrity of the glomerular filtration barrier is composed of several distinct proteins; the changes in these proteins play an important role in the pathogenesis of focal segmental glomerulosclerosis and minimal change disease which constitute the acquired podocytopathies. Specifically, the molecular changes observed in proteins from the cytoskeleton, cell transmembrane, and slit diaphragm induce foot process effacement and changes in negative charges resulting in massive proteinuria seen in these podocytopathies. The new knowledge about these molecular mechanisms has established the role of immunosuppressive drugs on podocytopathies and holds prospects for novel treatment approaches. 


\section{Acknowledgements}

The author wishes to acknowledge the invaluable information obtained from the paper - 'An overview of molecular mechanism of nephrotic syndrome’ by Machado JR et al. Int J Nephrol 2012; 2012 (Article ID 937623)

\section{Conflict of interest}

The author has none to declare

\section{References}

1. Eddy AA, Symons JM (2003) Nephrotic syndrome in childhood. Lancet 362: 629-639. [Crossref]

2. Antignac C (2002) Genetic models: clues for understanding the pathogenesis of idiopathic nephrotic syndrome. J Clin Invest 109: 447-449. [Crossref]

3. Machado JR, Rocha LP, Neves PD, Cobô Ede C, Silva MV, et al. (2012) An overview of molecular mechanism of nephrotic syndrome. Int J Nephrol 2012: 937623. [Crossref]

4. Brenchley PE (2003) Vascular permeability factors in steroid sensitive nephrotic syndrome and focal segmental glomerulosclerosis. Nephrol Dial Transplant 18: 21-25. [Crossref]

5. Wei C, E Hindi S, Li J, Fornoni A, Goes N, et al. (2011) Circulating urokinase receptor as a cause of focal segmental glomerulosclerosis. Nat Med 17: 952-960. [Crossref]

6. Van Den Berg JG, Aten J, Chand MA, Claessen N, Dijkink L, et al. (2000) Interleukin-4 and interleukin-13 act on glomerular visceral epithelial cells. J Am Soc Nephrol 11: 413-422. [Crossref]

7. Deschênes G, Martinat L (2000) [Molecular mechanisms of idiopathic nephrotic syndrome]. Arch Pediatr 7: 1318-1329. [Crossref]

8. Schönenberger E, Ehrich JH, Haller H, Schiffer M (2011) The podocyte as a direct target of immunosuppressive agents. Nephrol Dial Transplant 26: 18-24. [Crossref]

9. Shirato I (2002) Podocyte process effacement in vivo. Microsc Res Tech 57: 241-246. [Crossref]

10. Ma H, Togawa A, Soda K, Zhang J, Lee S, et al. (2010) Inhibition of podocyte FAK protects against proteinuria and foot process effacement. J Am Soc Nephrol 21: 11451156. [Crossref]

11. Donoviel DB, Freed DD, Vogel H, Potter DG, Hawkins E, Barrish JP, et al. (2001) Proteinuria and perinatal lethality in mice lacking NEPH1, a novel protein with homology to NEPHRIN. Mol Cell Biol 21: 4829-4836. [Crossref]

12. Shih NY, Li J, Karpitskii V, Nguyen A, Dustin ML, et al. (1999) Congenital nephrotic syndrome in mice lacking CD2-associated protein. Science 286: 312-315. [Crossref]

13. Shaw AS, Miner JH (2001) CD2-associated protein and the kidney. Curr Opin Nephrol Hypertens 10: 19-22. [Crossref]

14. Boute N, Gribouval O, Roselli S, Benessy F, Lee H, et al. (2000) NPHS2, encoding the glomerular protein podocin, is mutated in autosomal recessive steroid-resistant nephrotic syndrome. Nat Genet 24: 349-354. [Crossref]

15. Patrakka J, Tryggvason K (2007) Nephrin--a unique structural and signaling protein of the kidney filter. Trends Mol Med 13: 396-403. [Crossref]

16. Lehtonen S, Zhao F, Lehtonen E (2002) CD2-associated protein directly interacts with the actin cytoskeleton. Am J Physiol Renal Physiol 283: F734-743. [Crossref]

17. Yuan H, Takeuchi E, Salant DJ (2002) Podocyte slit-diaphragm protein nephrin is linked to the actin cytoskeleton. Am J Physiol Renal Physiol 282: F585-591. [Crossref]

18. Somlo S, Mundel P (2000) Getting a foothold in nephrotic syndrome. Nat Genet 24: 333-335. [Crossref]

19. Andrews PM (1981) Investigations of cytoplasmic contractile and cytoskeletal elements in the kidney glomerulus. Kidney Int 20: 549-562. [Crossref]

20. Mundel P, Heid HW, Mundel TM, Krüger M, Reiser J, et al. (1997) Synaptopodin: an actin-associated protein in telencephalic dendrites and renal podocytes. J Cell Biol 139: 193-204. [Crossref]

21. Smoyer WE, Mundel P, Gupta A, Welsh MJ (1997) Podocyte alpha-actinin induction precedes foot process effacement in experimental nephrotic syndrome. Am J Physiol 273: F150-157. [Crossref]

22. Srivastava T, Garola RE, Whiting JM, Alon US (2001) Synaptopodin expression in idiopathic nephrotic syndrome of childhood. Kidney Int 59: 118-125. [Crossref]

23. Kerjaschki D, Sharkey DJ, Farquhar MG (1984) Identification and characterization of podocalyxin--the major sialoprotein of the renal glomerular epithelial cell. J Cell Biol 98: 1591-1596. [Crossref]

24. Kavoura E, Gakiopoulou H, Paraskevakou H, Marinaki S, Agrogiannis G, et al. (2011) Immunohistochemical evaluation of podocalyxin expression in glomerulopathies associated with nephrotic syndrome. Hum Pathol 42: 227-235. [Crossref]

25. Thomas PE, Wharram BL, Goyal M, Wiggins JE, Holzman LB, et al. (1994) GLEPP1, a renal glomerular epithelial cell (podocyte) membrane protein- tyrosine phosphatase. Identification, molecular cloning, and characterization in rabbit. J Biol Chemistry 269: 19953-19962. [Crossref]

26. Wharram BL, Goyal M, Gillespie PJ, Wiggins JE, Kershaw DB, et al. (2000) Altered podocyte structure in GLEPP1 (Ptpro)-deficient mice associated with hypertension and low glomerular filtration rate. J Clin Invest 106: 1281-1290. [Crossref]

27. Barisoni L, Kriz W, Mundel P, D'Agati V (1999) The dysregulated podocyte phenotype: a novel concept in the pathogenesis of collapsing idiopathic focal segmental glomerulosclerosis and HIV-associated nephropathy. J Am Soc Nephrol 10: 51-61. [Crossref]

28. Barisoni L, Mundel P (2003) Podocyte biology and the emerging understanding of podocyte diseases. Am J Nephrol 23: 353-360. [Crossref]

29. Henry J, Miller MM, Pontarotti P (1999) Structure and evolution of the extended B7 family. Immunol Today 20: 285-288. [Crossref]

30. Wakem P, Burns RP, Ramirez F, Zlotnick D, Ferbel B, et al. (2000) Allergens and irritants transcriptionally upregulate CD80 gene expression in human keratinocytes. $J$ Invest Dermatol 114: 1085-1092. [Crossref]

31. Reiser J, von Gersdorff G, Loos M, Oh J, Asanuma K, et al. (2004) Induction of B7-1 in podocytes is associated with nephrotic syndrome. J Clin Invest 113: 1390-1397. [Crossref]

32. Yap HK, Cheung W, Murugasu B, Sim SK, Seah CC, et al. (1999) Th1 and Th2 cytokine mRNA profiles in childhood nephrotic syndrome: evidence for increased IL-13 mRNA expression in relapse. J Am Soc Nephrol 10: 529-537. [Crossref]

33. Le Berre L, Hervé C, Buzelen F, Usal C, Soulillou JP, et al. (2005) Renal macrophage activation and Th2 polarization precedes the development of nephrotic syndrome in Buffalo/Mna rats. Kidney Int 68: 2079-2090. [Crossref]

34. Lai KW1, Wei CL, Tan LK, Tan PH, Chiang GS, et al. (2007) Overexpression of interleukin-13 induces minimal-change-like nephropathy in rats. J Am Soc Nephrol 18: 1476-1485. [Crossref]

35. Pereira RL, Reis VO, Semedo P, Buscariollo BN, Donizetti-Oliveira C, et al. (2012) Invariant natural killer $\mathrm{T}$ cell agonist modulates experimental focal and segmental glomerulosclerosis. PLoS One 7: e32454. [Crossref]

36. Mesnard L, Keller AC, Michel ML, Vandermeersch S, Rafat C, et al. (2009) Invarian natural killer T cells and TGF-beta attenuate anti-GBM glomerulonephritis. J Am Soc Nephrol 20: 1282-1292. [Crossref]

37. Schiffer M, Von Gersdorff G, Bitzer M, Susztak K, Bottinger EP (2000) Smad protein and transforming growth factor- $\beta$ signaling. Kidney Int 58: S45-S52. [Crossref]

38. Kang YS, Li Y, Dai C, Kiss LP, Wu C, et al. (2010) Inhibition of integrin-linked kinase blocks podocyte epithelial-mesenchymal transition and ameliorates proteinuria. Kidney Int 78: 363-373. [Crossref]

39. Li Y, Kang YS, Dai C, Kiss LP, Wen X, et al. (2008) Epithelial-to-mesenchyma transition is a potential pathway leading to podocyte dysfunction and proteinuria. $\mathrm{Am}$ J Pathol 172: 299-308. [Crossref]

40. Yamaguchi Y, Iwano M, Suzuki D, Nakatani K, Kimura K, et al. (2009) Epithelialmesenchymal transition as a potential explanation for podocyte depletion in diabetic nephropathy. Am J Kidney Dis 54: 653-664. [Crossref]

41. Reidy K, Susztak K (2009) Epithelial-mesenchymal transition and podocyte loss in diabetic kidney disease. Am J Kidney Dis 54: 590-593. [Crossref]

42. Kang HG, Cheong HI1 (2015) Nephrotic syndrome: what's new, what's hot? Korean J Pediatr 58: 275-282. [Crossref]

43. Clement LC, Mace C, Del Nogal Avila M, Marshall CB, Chugh SS (2015) The proteinuria-hypertriglyceridemia connection as a basis for novel therapeutics for nephrotic syndrome. Transl Res 165: 499-504. [Crossref]

44. Clement LC, Macé C, Avila-Casado C, Joles JA, Kersten S, et al. (2014) Circulating 
angiopoietin-like 4 links proteinuria with hypertriglyceridemia in nephrotic syndrome. Nat Med 20: 37-46. [Crossref]

45. Greenbaum LA, Benndorf R, Smoyer WE (2012) Childhood nephrotic syndrome-current and future therapies. Nat Rev Nephrol 8: 445-458. [Crossref]

46. Machuca E, Benoit G, Antignac C (2009) Genetics of nephrotic syndrome: connecting molecular genetics to podocyte physiology. Hum Mol Genet 18: R185-194. [Crossref]

47. Löwik MM, Groenen PJ, Levtchenko EN, Monnens LA, van den Heuvel LP (2009) Molecular genetic analysis of podocyte genes in focal segmental glomerulosclerosis--a review. Eur J Pediatr 168: 1291-1304. [Crossref]

48. Chiang CK, Inagi R (2010) Glomerular diseases: genetic causes and future therapeutics. Nat Rev Nephrol 6: 539-554. [Crossref]
49. McCarthy HJ, Saleem MA (2011) Genetics in clinical practice: nephrotic and proteinuric syndromes. Nephron Exp Nephrol 118: e1-8. [Crossref]

50. Pei Y (2011) INF2 is another piece of the jigsaw puzzle for FSGS. J Am Soc Nephrol 22: 197-199. [Crossref]

51. Akilesh S, Suleiman H, Yu H, Stander C, Lavin P, et al. (2011) ARHGAP 24 inactivates RAC 1 in mouse podocytes and mutant form is associated with familial focal segmental glomerulosclerosis. J Clin Invest 121:4127-4137. [Crossref]

52. Hasselbacher K, Wiggins RC, Matejas V, Hinkes BG, Mucha B, et al. (2006) Recessive missense mutations in LAMB2 expand the clinical spectrum of LAMB2-associated disorders. Kidney Int 70: 1008-1012. [Crossref]

Copyright: $(2015$ Uwaezuoke SN. This is an open-access article distributed under the terms of the Creative Commons Attribution License, which permits unrestricted use, distribution, and reproduction in any medium, provided the original author and source are credited. 